\title{
How health system factors affect primary care practitioners' decisions to refer patients for further investigation: protocol for a pan-European ecological study
}

\author{
Michael Harris ${ }^{*}$ (D), Gordon Taylor and The Örenäs Research Group
}

\begin{abstract}
Background: There is wide variation in the overall one-year relative cancer survival rates across Europe, and this is thought to indicate national variations in stage of disease at diagnosis. However, there is little evidence to explain how different national systems influence a primary care practitioner's (PCP's) referral decisions, and how these relate to the variation in survival rates.

This study investigates the health system factors that influence the thinking of PCPs when faced with patients who may have cancer, how they compare across European countries, and how they relate to national one-year relative cancer relative survival rates.
\end{abstract}

Methods: An online quantitative questionnaire with closed-ended questions is used in a cross-sectional survey of 1250 PCPs in Europe, in 25 local health areas in 20 countries. Descriptive data are elicited for each country, including respondents' demographic details.

An exploratory factor analysis will identify factors underlying the decision to refer patients for further investigations. Between-country variation in these factors will then be further investigated and presented as means with 95\% confidence intervals. A regression model will be fitted for the vignettes using one-year relative survival as the outcome, with the proportion of PCPs opting to investigate as a single explanatory variable. Weighted regression will be used to explore which health system factors are associated with opting to investigate and with one-year relative survival.

Linear correlations will be estimated between the proportions opting to investigate and national survival rates. When comparing between countries, weighted linear regression will be used to adjust for different sample sizes in each country.

Discussion: This study investigates which system factors affect PCPs' decisions to refer and investigate patients who may have cancer, how they compare across 20 European countries, and how these factors relate to cancer survival rates.

Knowledge of the extent and variability of the health system factors that affect referral decisions will inform future health service design, policy and research.

Keywords: Delivery of health care, Primary health care, Cancer, Decision making, Diagnosis, Survival

\footnotetext{
* Correspondence: michaelharris681@btinternet.com

Department for Health, University of Bath, Claverton Down, Bath BA2 7AY,

UK
}

(c) The Author(s). 2018 Open Access This article is distributed under the terms of the Creative Commons Attribution 4.0 International License (http://creativecommons.org/licenses/by/4.0/), which permits unrestricted use, distribution, and reproduction in any medium, provided you give appropriate credit to the original author(s) and the source, provide a link to the Creative Commons license, and indicate if changes were made. The Creative Commons Public Domain Dedication waiver (http://creativecommons.org/publicdomain/zero/1.0/) applies to the data made available in this article, unless otherwise stated. 


\section{Background}

\section{Variation in European survival rates}

There is wide variation in the relative cancer survival rates across Europe [1]. For example, in the United Kingdom, more than 6000 deaths within five years of diagnosis would have been avoided annually if survival in Britain had matched the European mean [2], representing $6-7 \%$ of deaths due to cancer. The European 1year relative cancer survival rates vary even more than those for 5-year survival: analysis of the EUROCARE-5 data shows that the 1 -year relative survival rate for all cancer sites varies from 60.0 to $80.5 \%$ between European countries, and there is with large variation even within EUROCARE's five main European regions [1]. One-year relative cancer survival rates may be affected by differences in registration (e.g. completeness and use of death certificates), and lead-time and over-diagnosis biases [3, 4], however they are commonly thought to be a marker of more advanced disease at diagnosis $[5,6]$.

Analysis of European one-year relative cancer survival results [1,7-9] shows that some countries have high survival rates for most cancers (including Belgium, France, Sweden and Switzerland), while others have lower survival rates (including Bulgaria, Croatia, Poland and Scotland). Recent cancer survival rates have shown improvement [9], but the between-country survival differences have shown little change [10]. Survival variation in the subsequent four-year period is narrower, and this suggests that an improvement in cancer awareness and early detection in relatively poorly performing countries could reduce the observed one-year relative survival gap [8].

\section{Consequences of late diagnosis}

The assumption that earlier diagnosis of cancer in symptomatic patients leads to improved survival is difficult to confirm [11]. A systematic review found that, while the survival benefits of earlier diagnosis varies between cancers, there is an association between a shorter diagnostic interval and improved outcomes for breast, colorectal, head and neck, and testicular cancers, as well as for melanoma [12]. In addition, a study of data for breast, colorectal and lung cancer in England determined that late diagnosis was highly likely to be a major factor explaining poorer survival in those cancers [5].

There are considerable difficulties in deciding how to achieve more timely cancer diagnoses [13]. A Primary Care Practitioner (PCP) will see only a small number of new cancers in any one year $(309,500$ UK patients were diagnosed with cancer in 2008 [14], giving a mean of 7.5 per PCP), and a General Practitioner (GP) may rarely or never see some uncommon cancers. In most patients who present with cancer-related symptoms those symptoms are undifferentiated, which makes them less likely to be initially interpreted being due to cancer [13].

\section{Access to specialist care and investigations}

Healthcare systems with strong primary care have lower mortality and morbidity rates [15], and GP gatekeeping is the cornerstone of many European medical systems [16]. There has been some evidence that countries with gatekeeper systems have lower one-year relative cancer survival than those that do not have GPs as gatekeepers [17]. This may be because gatekeeping systems can impose cost and resource decisions which impede early referral for investigation [18]. Gatekeeping may act against early cancer diagnosis by changing the balance between referral for opinion or investigation, and minimising costs and the risk of iatrogenic illness [19].

However, a European study found large national differences in the extent of gatekeeping, with no uniform "GP-as-gatekeeper" model, and no link between a higher probability of initial consultation with a GP and reduced cancer survival [20].

There is little evidence on how different healthcare systems influence a primary care practitioner's referral decisions, or on how they may contribute to the marked variations in one-year cancer survival [13].

\section{The effect of different beliefs, health systems and behaviour in primary care}

The International Cancer Benchmarking Partnership (ICBP) is using predominantly quantitative methods to measure beliefs, behaviours and systems in primary care as they relate to delays in diagnosis [21]. The ICBP's work has examined the differences in cancer awareness and beliefs between six countries with comparable wealth to detect where these might help to explain to those countries' survival patterns [22].

\section{Study rationale and evidence gap}

In order to improve outcomes for patients, a better understanding of how individual health system factors and patient and professional behaviour interact is needed [23]. One possible explanation of differences in survival between countries is differing levels of diagnostic activity, and there is a need for studies that fully interpret the possible reasons for differences in cancer survival and suggest how to remedy disparities [9].

A recently published ICBP study showed a correlation between cancer survival rates and how ready PCPs are to investigate symptoms that could be due to cancer [24]. While the study found no correlation between some health system factors and readiness to refer, there was no exploration of how individual doctors felt that those system factors affected their decision-making. However, a large variety of non-clinical factors that are likely to affect PCPs' referral decisions have been identified [25]. These include the extent to which PCPs are gatekeepers, funding systems, access to special 
investigations, concerns over the risk of litigation, and the barriers to accessing specialist opinions.

To develop a more detailed understanding of these issues, this study investigates which system factors affect PCPs' decisions to refer patients who may have cancer for further investigation (specialist opinion or special investigation) in twenty European countries, how they compare across those countries, and how those factors relate to one-year relative cancer survival rates.

Knowledge of the extent and variability of the health system factors that affect referral decisions will inform future health service design, policy and research.

\section{Methods and design}

The study uses a questionnaire survey of PCPs in twenty European countries with diverse cancer survival rates. The questionnaire was administered online. Recruitment started in November 2015 and was completed at the end of 2016.

\section{Study population}

The Örenäs Research Group is a pan-European collaborative of primary care researchers, formed in 2013 to study the factors influencing national variations in the early diagnosis of cancer in primary care. The research is being conducted in 25 Örenäs Research Group centres in 20 countries across Europe: Bulgaria, Croatia, Denmark, England, Finland, France, Germany, Greece, Israel, Italy, Netherlands, Norway, Poland, Portugal, Romania, Scotland, Slovenia, Spain, Sweden and Switzerland. Medical doctors were eligible for the survey if they were doctors working mainly in primary care. These doctors, here referred to collectively as 'Primary Care Practitioners', included GPs and other doctors who had had specialist training but worked in the community and could be accessed directly by patients without referral.

\section{Sampling methods}

Each local lead was asked to email an invitation to take part in the survey to all the PCPs in their local health district, and to recruit at least fifty participants. Low survey response rates are common in primary care [26] and can vary between jurisdictions, with a recent ICBP survey response rate varying from 5.5 to $45.6 \%$ depending on country [24]. Any local leads who had difficulty in achieving the required sample sizes were therefore asked to increase the number of responses by using snowballing, a recognised technique for recruiting hard-to-reach populations in health studies $[27,28]$.

\section{Sample size}

A total sample size of 1000 or more responses was calculated to be sufficient to obtain stable factor estimates within the exploratory factor analysis [29]. Given the 20 items in the questionnaire, this is also considerably in excess of the Hair et al. (1998) rule of requiring a sample size of at least ten times the number of variables [30]. Based on a minimum of 50 responses for each jurisdiction this will provide us with $95 \%$ confidence intervals (CI) $\pm 14 \%$ for equally distributed responses, and $95 \%$ CI $\pm 13 \%$ for less equally distributed responses, enabling informal exploratory comparisons between jurisdictions.

\section{Exploratory work: results and study adaptation}

The study was designed by Örenäs Research Group investigators at a meeting in May 2014. They developed and agreed by consensus a list of factors that may affect a PCP's decisions to refer patients for further investigation. A literature review did not reveal any missing factors. A questionnaire with five clinical vignettes (two of which were adapted, with permission, from ICBP vignettes) and 45 decision-making factors was piloted by the Örenäs Research Group local leads in January 2015 to check validity. One of the vignettes and six of the factors were found to be invalid and were removed.

A questionnaire, in English, with the remaining 39 decision-making statements was piloted by 49 PCPs in 16 Örenäs Research Group member countries in July 2015 , to identify the statements on which there was little or no difference in responses between countries. Of those, 19 statements were found to show little or no variation between countries so were removed from the questionnaire, leaving 20 statements.

Örenäs Research Group leads arranged for translations of the questionnaire into their local languages where these were not English, a total of 19 translations from the original English. Translation and validation were done in a standardised way [31]: medically qualified native speakers of the local languages who were fluent in English did the 'forward' translations. 'Backward' translations into English were then made by translators who were fluent in both English and their local languages. The forward translations were then compared with the backward ones, to assess semantic and conceptual equivalence [32]. Discrepancies between the forward and backward translations were resolved by discussion with the translators, following which the final translations were agreed on. The validated questionnaires were then put on-line by $\mathrm{MH}$ using the survey tool provided by SurveyMonkey, and each national lead was issued with their own web link. Because of the widespread geographical coverage, on-line methodology was used to aid the logistics of survey administration; on-line surveys have been successfully used in healthcareprofessional research [33]. 
Local Örenäs Research Group leads each then sent their survey link and a translated participant information sheet to local PCPs, including doctors who had had specialist training but worked in the community and could be accessed directly by patients without referral. Consent was implied by agreeing to take part in the survey.

As well as managing recruitment of participants in their respective countries, Örenäs Research Group local leads will contribute to the interpretation of the results and their dissemination.

\section{Description of the questionnaire}

The questionnaire is made up of 47 items and divided into four sections:

A. Demographic questions: five questions ask about years since graduation, gender, speciality, type and rural/urban location of practice and number of doctors working in practice.

B. Referral availability questions: two questions ask about tests and specialist opinions that are either directly or indirectly available to the respondent.

C. Clinical vignette questions: this section describes four patients who have symptoms suggestive of lung, colorectal, ovarian and breast cancer respectively; for each patient, a range of five possible management decisions (including whether the respondent would investigate or refer the patient, or would use watchful waiting) is given, with a 'yes/no' option for each.

D. Health system factor questions: twenty statements relating to health system factors that may affect referral decisions are given, with a request for the respondent to state how much they agree with each statement. A five-point Likert rating scale is provided for participants, with response options ranging from 'Strongly agree' to 'Strongly disagree'.

The health system factor statements are divided into seven sections:

1. Guidelines and local systems (example: 'The local health system encourages us to refer any patients with possible cancer early, even if there is a low risk of cancer').

2. Relationship with specialist colleagues (example: 'Here, specialists usually welcome referrals).

3. Financial issues (example: 'Here, high quality care for an individual patient is always more important than costs').

4. Concerns about complaints (example: 'My colleagues sometimes criticise me if I have referred a patient to them, but they think that I should have been able to manage the patient myself').
5. Waiting lists (example: 'We have access to a fasttrack specialist appointment system for patients with suspected cancer').

6. The effect of PCPs' workload (example: 'I am usually very busy, so I sometimes refer to help reduce my workload').

7. Patient and doctor feelings (example: 'I am likely to refer if the patient says that she/he would like to be referred, even if there are no "red flags"').

\section{Statistical analysis}

Descriptive data will be provided on each country, including the number and characteristics of the PCPs completing the survey.

An exploratory factor analysis will be undertaken on the questionnaire responses, to identify underlying factors relating to the decision to refer patients for further investigations. We will use a principal components method [34], with a direct oblimin rotation to allow for correlated factors. The number of components will be defined by inspection of the scree plot and the Kaiser criterion (eigenvalue $\geq 1$ ). Between-country variation in these factors will then be further investigated and presented as means with $95 \%$ confidence intervals. A regression model will be fitted for the vignettes using overall national one-year relative cancer survival, calculated from EUROCARE data [1], as the outcome, with the proportion of PCPs opting to investigate as a single explanatory variable. Weighted regression will be used to explore which health system factors are associated with opting to investigate and with one-year relative survival. The primary outcome measure will be one-year relative cancer survival, as it is thought to reflect activity in primary care. We will make a sensitivity analysis using five-year relative cancer survival.

We will estimate the linear correlations between the proportions of PCPs opting to investigate and national survival rates. For national comparisons, weighted linear regression will be used to adjust for different sample sizes in each country.

\section{Discussion}

This research will consider how Europe's differing models of primary care result in differences in the thresholds that PCPs have for considering a diagnosis of cancer and for investigating that possibility. By understanding the key differences and similarities between European countries with different cancer survival rates, we will be able to offer suggestions on how improvements can be made. The research findings will help all European countries improve their cancer survival rates by optimising cancer diagnosis policies and services. 


\section{Strengths}

To our knowledge, this is the first study that has been designed to examine the factors underlying PCPs' referral decision-making, and to provide international comparisons of the extent to which PCPs themselves perceive these as important.

There are participating centres in four countries from each of the Central, Eastern, Northern, Southern and Western European geographical areas, providing variation in geography, health systems and levels of healthcare spending. It includes the views of PCPs who are not usually involved in research. The questionnaire was carefully developed and piloted by GPs and other PCPs, and therefore grounded in their clinical experience.

\section{Limitations}

Collaborators are asked to recruit local primary care doctors by convenience sampling, and there may be selection bias [35]. The recruitment method used in this study (an emailed, unreimbursed survey, with a confidential approach that precludes follow-up of nonresponders) may result in low response rates, leading to non-response bias and loss of power [26]. The survey has 47 items, which may cause response fatigue, and there may be bias due to hypothesis guessing [36]. There may also be a response bias, including social desirability bias [37], in participants' answers to the vignettes and health system factor questions. While Likert scales are likely to be easily understood by participants and the responses are easily quantifiable, only five response options are given in the questionnaire, and these may fail to measure respondents' true attitudes. Participants' responses may be influenced by previous questions, and there may be country-level differences in response styles, for instance choosing or avoiding the 'extreme' options on the scale. [38].

Vignette-based methodologies are frequently used to examine judgments and decision-making processes, and here are used as proxies for real patients, but the vignettes may not be typical of patients seen by participant PCPs in their everyday practice. Despite this potential limitation, well-designed vignette studies that ask questions about judgments and decision-making can be highly generalisable to 'real-life' behaviour $[39,40]$, while avoiding the ethical and practical restrictions associated with other methods.

While EUROCARE- 5 provides survival data for almost nine million adults in 29 countries, 8 of these countries have only partial coverage [9], and this may affect the generalizability of their data. One-year relative survival rates for cancer can be affected by lead-time and overdiagnosis biases [3, 4]. Although we will make a sensitivity analysis using five-year relative survival, this may not completely negate the risk of these biases.

\section{Expected impact}

The study should indicate how much variation there is in PCP decision-making in participant countries, and how much of this variation can be explained by differences between the health systems. The results will indicate the policy domains where countries might be able to modify their systems to better support their GPs and other PCPs in the timely referral and investigation of patients who could have cancer.

The Örenäs Research Group will be able to compare the factor analysis scores with national cancer outcomes. These outcomes could include mortality, stage distribution and patient evaluations. An additional area of study could be to relate the factors and scores to national health system costs.

\section{Quality assurance}

During the preparation of the study, quality has been ensured through the process of translation and backtranslation of the questionnaire described above. The local leads for each participating centre proofread the translated documents to confirm that they reflected the terminology used in their health regions. The survey was then piloted by PCPs in each centre to check for clarity, formatting errors and cultural equivalence.

The Örenäs Research Group local leads share all decisions about research developments and outputs, with decisions made by consensus where possible, and by majority vote where this is not possible.

\section{Confidentiality}

No personally identifiable information is collected from participants: the survey is anonymous.

\section{Dissemination}

Sharing information about the project will take place throughout the duration of the work and not just at the end. Results will be published in peer-reviewed scientific journals as well as by conference presentations and will be communicated to respondents and relevant institutions through cooperation with the European General Practice Research Network. Local leads will be encouraged to publicise the project findings within their universities and health services, for example in newsletters, websites, meetings and local journal publications.

\section{Abbreviations \\ GP: General Practitioner; ICBP: International Cancer Benchmarking} Partnership; PCP: Primary Care Practitioner

\section{Acknowledgements}

The authors and their Örenäs Research Group collaborators would like to thank their colleagues who piloted and commented on the study and questionnaire design.

Two of the clinical cases are used by kind permission of the International Cancer Benchmarking Partnership. The authors are also grateful to Dr. Peter Murchie and Dr. Rhona Auckland, who generously provided the other two 
vignettes. Dr. Magdalena Esteva, Dr. Mercè Marzo-Castillejo and Dr. Peter Murchie provided detailed comments on the manuscript.

The following Örenäs Research Group members participated in designing and/or piloting the study, and are non-author collaborators: Isabelle AubinAuger, Université Paris Diderot, France; Joseph Azuri and Robert Hoffman, Tel Aviv University, Israel; Erika Baum, Philipps Universität Marburg, Germany; Krzysztof Buczkowski, Nicolaus Copernicus University, Poland; Nicola Buono, Caserta, Italy; Emiliana Costiug, Cluj-Napoca, Romania; Geert-Jan Dinant, Maastricht University, Netherlands; Magdalena Esteva, Majorca Primary Health Care Department, Palma Mallorca, Spain; Svjetlana Gašparović Babić, University of Rijeka, Croatia; Gergana Foreva, Medical University of Plovdiv, Bulgaria; May-Lill Johansen, University of Tromsø, Norway; Mercè Marzo-Castillejo, IDIAP Jordi Gol, Barcelona, Spain; Peter Murchie, University of Aberdeen, Scotland; Davorina Petek and Marija Petek Ster, University of Ljubljana, Slovenia; Jolanta Sawicka-Powierza, Medical University of Bialystok, Poland; Emmanouil Smyrnakis, Aristotle University of Thessaloniki, Greece; Hans Thulesius, Lund University, Sweden; Peter Vedsted, Danish Research Centre for Cancer Diagnosis in Primary Care (CaP), Denmark; Birgitta Weltermann, University of Duisburg-Essen, Germany.

\section{Funding}

This research receives no specific grant from any funding agency in the public, commercial or not-for-profit sectors.

\section{Availability of data and materials}

Only the research team at the University of Bath will have access to the data during the study. After the study is completed, the University of Bath will make the relevant data available to Örenäs Research Group collaborators for local analysis.

The datasets analysed during this study will be available from the corresponding author on reasonable request.

\section{Authors' contributions}

Both named authors have made substantial contributions to the study, as well as drafting the article and revising it critically for important intellectual content. MH has overall responsibility for the design, recruitment of local leads, analysis of data and interpretation of results, as well as writing the report. GT has advised on the study design and the statistical analysis. All authors have read and approved of the final version of the manuscript. Örenäs Research Group members have been involved in the design and/or piloting of the study, and have seen, and been invited to comment on, this paper.

\section{Ethics approval and consent to participate}

Ethical approval for the study has been given by the University of Bath Research Ethics Approval Committee for Health (approval date: 24th November 2014; REACH reference number: EP 14/15 66). Other countries' study leads have been asked to achieve local ethical approval when needed. As well as a model email survey invitation to be translated and sent to potential participants, Örenäs Research Group local leads have been provided with a model Participant Information Sheet. Respondents who accept the invitation to take part in the study are taken to the survey introductory page, where they are given information about the project, information on the time it will take to complete the questionnaire, an assurance that their answers are confidential, and a statement that their names and contact details will not be requested. Participants are asked to click on a link to confirm that they agree to take the survey before they are able to continue. This action is considered as consent to participate in the study.

\section{Competing interests}

The authors declare that they have no competing interests.

\section{Publisher's Note}

Springer Nature remains neutral with regard to jurisdictional claims in published maps and institutional affiliations.
Received: 3 August 2016 Accepted: 1 May 2018

Published online: 08 May 2018

\section{References}

1. EUROCARE. EUROCARE-5. Istituto Nazionale Tumori (Milan IalSdSR, Italy). Milan and Rome; 2014

2. Abdel-Rahman M, Stockton D, Rachet B, Hakulinen T, Coleman MP. What if cancer survival in Britain were the same as in Europe: how many deaths are avoidable? Br J Cancer. 2009;101(S2):S115-S24

3. Carter $J$, Coletti RJ, Harris RP. Quantifying and monitoring overdiagnosis in cancer screening: a systematic review of methods. BMJ. 2015;350:97773. https://doi.org/10.1136/bmj.g7773.

4. Zahl PH, Jorgensen KJ, Gotzsche PC. Overestimated lead times in cancer screening has led to substantial underestimation of overdiagnosis. Br J Cancer. 2013;109(7):2014-9. https://doi.org/10.1038/bjc.2013.427. Epub Aug 20.

5. Richards MA. The size of the prize for earlier diagnosis of cancer in England. Br J Cancer. 2009:101:S125-S9.

6. Woods LM, Coleman MP, Lawrence G, Rashbass J, Berrino F, Rachet B. Evidence against the proposition that "UK cancer survival statistics are misleading": simulation study with National Cancer Registry data. BMJ. 2011; 342:d3399. https://doi.org/10.1136/bmj.d3399.

7. EUROCARE. EUROCARE-4 Survival of cancer patients in Europe. Istituto Nazionale Tumori. Milan IalSdSR, Italy: Eurocare; 2011.

8. Thomson CS, Forman D. Cancer survival in England and the influence of early diagnosis: what can we learn from recent EUROCARE results? $\mathrm{Br}$ J Cancer. 2009:101:S102-59.

9. De Angelis R, Sant M, Coleman MP, Francisci S, Baili P, Pierannunzio D, et al. Cancer survival in Europe 1999-2007 by country and age: results of EUROCARE-5 - a population-based study. Lancet Oncol. 2014;15(1):23-34.

10. Coleman MP, Forman D, Bryant H, Butler J, Rachet B, Maringe C, et al. Cancer survival in Australia, Canada, Denmark, Norway, Sweden, and the UK, 1995-2007 (the international Cancer benchmarking partnership): an analysis of population-based cancer registry data. Lancet. 2011;377(9760):127-38.

11. Rubin G, Vedsted P, Emery J. Improving cancer outcomes: better access to diagnostics in primary care could be critical. Br J Gen Pract. 2011;61(586):317-8.

12. Neal RD, Tharmanathan P, France B, Din NU, Cotton S, Fallon-Ferguson J, et al. Is increased time to diagnosis and treatment in symptomatic cancer associated with poorer outcomes? Systematic review. Br J Cancer. 2015; 112(Suppl 1):S92-107.

13. Foot C, Harrison T. How to improve cancer survival: explaining England's relatively poor rates. London: The King's Fund; 2011. p. 30. January 2012

14. Cancer Research UK. CancerStats key facts: all cancers combined. Cancer Research UK: United Kingdom; 2012.

15. Starfield B, Shi L, Macinko J. Contribution of primary care to health systems and health. Milbank Q. 2005;83(3):457-502.

16. Masseria C, Irwin R, Thomson S, Gemmill M, Mossialos E. Primary care in Europe. European Commission: Science TLSoEaP; 2009.

17. Vedsted $\mathrm{P}$, Oleson F. Are the serious problems in cancer survival partly rooted in gatekeeper principles? Br J Gen Pract. 2011;61(589):512-3.

18. Neal RD. Commentary. Cancer diagnosis - the role of urgent referral guidelines. Br J Gen Pract. 2010;60(571):127.

19. Hamilton W. Cancer diagnosis in primary care. Br J Gen Pract. 2010;60(571): $121-8$.

20. Harris M, Frey P, Esteva M, Gašparović Babić S, Marzo-Castillejo M, Petek D, et al. How the probability of presentation to a primary care clinician correlates with cancer survival rates: a European survey using vignettes. Scand J Prim Health Care. 2017:35:1-8.

21. International Cancer Benchmarking P. ICBP Newsletter. London: Cancer Research UK: 2011.

22. Forbes LJL, Simon AE, Warburton F, Boniface D, Brain KE, Dessaix A, et al. Differences in cancer awareness and beliefs between Australia, Canada, Denmark, Norway, Sweden and the UK (the international Cancer benchmarking partnership): do they contribute to differences in cancer survival? Br J Cancer. 2013;108(2):292-300.

23. Brown $S$, Castelli M, Hunter D, Erskine J, Vedsted P, Foot C, et al. How might healthcare systems influence speed of cancer diagnosis: a narrative review. Soc Sci Med. 2014;116:56-63.

24. Rose PW, Rubin G, Perera-Salazar R, Almberg SS, Barisic A, Dawes M, et al. Explaining variation in cancer survival between 11 jurisdictions in the international Cancer benchmarking partnership: a primary care vignette survey. BMJ Open. 2015;5(5):e007212. https://doi.org/10.1136/bmjopen-2014-. 
25. Harris M, Frey P, Esteva M, Gašparović-Babić S, Marzo-Castillejo M, Petek D, et al. How health system factors influence referral decisions in patients that may have cancer: European symposium report. J Cancer Res Ther. 2016;4(1): 7-10.

26. Pit SW, Vo T, Pyakurel S. The effectiveness of recruitment strategies on general practitioner's survey response rates - a systematic review. BMC Med Res Methodol. 2014;14:76.

27. Shaghaghi A, Bhopal RS, Sheikh A. Approaches to recruiting 'hard-to-reach' populations into research: a review of the literature. Health Promot Perspect. 2011;1(2):86-94.

28. Atkinson R, Flint J. Accessing hidden and hard-to-reach populations: snowball research strategies. Guildford, UK: University of Surrey; 2001.

29. van Belle G. Statistical rules of thumb, 2nd Edition. Hoboken, NJ: Wiley; 2008.

30. Hair J, Black W, Babin B, Anderson R. Multivariate Data Analysis. 7th ed. Harlow: Pearson Education Ltd: 2009.

31. Maneesriwongul W, Dixon JK. Instrument translation process: a methods review. J Adv Nurs. 2004:48(2):175-86.

32. Center for Aging in Diverse Communities. Guidelines for translating surveys in cross-cultural research. San Francisco: University of California; 2007.

33. Dobrow MJ, Orchard MC, Golden B, Holowaty E, Paszat L, Brown AD, et al. Response audit of an internet survey of health care providers and administrators: implications for determination of response rates. J Med Internet Res. 2008;10(4):e30.

34. Hotelling $\mathrm{H}$. Analysis of a complex of statistical variables into principal components. J Educ Psychol. 1933;24(6):417-41.

35. Greenacre Z. The importance of selection Bias in internet surveys. Open 」 Stat. 2016;6:397-404.

36. Choi BCK, Pak AWP. A catalog of biases in questionnaires. Prev Chronic Dis. 2005;2(1):A13

37. Althubaiti A. Information bias in health research: definition, pitfalls, and adjustment methods. J Multidiscip Healthc. 2016;9:211-7.

38. Harzing A-W. Response styles in cross-national survey research: a 26-country study. Int J Cross Cult Manag. 2006;6(2):243-65.

39. Evans SC, Roberts MC, Keeley JW, Blossom JB, Amaro CM, Garcia AM, et al. Vignette methodologies for studying clinicians' decision-making: validity, utility, and application in ICD-11 field studies. Int J Clin Health Psychol. 2015; 15(2):160-70.

40. Hrisos S, Eccles MP, Francis JJ, Dickinson HO, Kaner EF, Beyer F, et al. Are there valid proxy measures of clinical behaviour? A systematic review Implement Sci. 2009;4:37.

Ready to submit your research? Choose BMC and benefit from:

- fast, convenient online submission

- thorough peer review by experienced researchers in your field

- rapid publication on acceptance

- support for research data, including large and complex data types

- gold Open Access which fosters wider collaboration and increased citations

- maximum visibility for your research: over $100 \mathrm{M}$ website views per year

At BMC, research is always in progress.

Learn more biomedcentral.com/submissions 